\title{
Mucus glycoprotein biosynthesis in the human gall bladder: inhibition by aspirin
}

\author{
M Rhodes, A Allen, T W J Lennard
}

\begin{abstract}
Aspirin, which inhibits mucin secretion in the gastrointestinal tract prevents gall stone formation in animals and may reduce gall stone recurrence in man. This study examines the effect of aspirin on mucin synthesis in human gall bladder explants. Two hundred explants were cultured with ${ }^{3} \mathrm{H}$-glucosamine $(74 \mathrm{kBq} /$ $\mathrm{ml}$ ) for 24 hours at $37^{\circ} \mathrm{C}$. Mucin and other glycoproteins were isolated by papain digestion (72 hours) and exhaustive dialysis (144 hours) to remove non-incorporated radioactivity and digested protein. ${ }^{3} \mathrm{H}$-glucosamine was readily incorporated into glycoprotein. Pooled gall bladder explants were fractionated on a $\mathrm{CsCl}$ density gradient and by gel filtration on Sepharose $2 B$ and $4 B$ to confirm that $>90 \%$ radioactivity was incorporated into mucin. Acetylsalicylic acid (230-666 $\mu \mathrm{g} / \mathrm{ml})$ significantly reduced total ${ }^{3} \mathbf{H}$-glucosamine incorporation (43-89\%), p $<0.01$ (unpaired $t$ test). Diclofenac $\quad(125-1250 \mu \mathrm{g} / \mathrm{ml})$, similarly reduced incorporation by $45-97 \% \mathrm{p}<0.001$ (unpaired $t$ test). Inhibition of mucin glycoprotein biosynthesis was irreversible with both drugs. Analysis of pooled samples on Sepharose 4B showed abolition of radioactive incorporation into mucin but no effect on incorporation into low molecular weight glycoprotein material (10\% of total incorporation). This study provides a method for measuring human gall bladder mucin synthesis and shows its irreversible inhibition by acetylsalicylic acid and diclofenac at concentrations compatible with a therapeutic dose.

(Gut 1992; 33: 1109-1112)
\end{abstract}

Mucin has been identified in cholesterol and pigment gall stones using histochemical stains. ${ }^{12}$ In vitro studies have shown that mucus glycoprotein interacts with bilirubin ${ }^{3}$ and there is mounting evidence that it is involved in the nucleation of cholesterol. ${ }^{+6}$ Early work in man $^{7}$ revealed a higher concentration of hexosamine (a major constituent of mucin) in bile from gall stone patients as compared with controls. Both the cholesterol fed rabbit ${ }^{8}$ and cholesterol fed prairie $\operatorname{dog}^{9}$ secrete an increased amount of mucin before gall stone formation. This is accompanied by increased mucin biosynthesis in the prairie dog.

In the prairie dog mucin biosynthesis is stimulated by arachidonic acid and inhibited by aspirin. ${ }^{10}$ "In man there is some early information to suggest that aspirin may reduce the risk of gall stone formation during weight $\operatorname{loss}^{12}$ and decrease the risk of stone recurrence after successful dissolution therapy. ${ }^{13}$ The action of aspirin may be partially mediated through inhibition of eicosanoid metabolism, as in the prairie dog or through the drugs antiinflammatory properties. ${ }^{14}$ There is, however, little information available about the action of aspirin on the human gall bladder. We have therefore studied mucin biosynthesis in human gall bladder explants in 24 hour organ culture.

\section{Methods}

MATERIALS

D- $\left[6-{ }^{3} \mathrm{H}\right]$-glucosamine hydrochloride (specific activity $1110 \mathrm{GBq} / \mathrm{mmol}$ ) was obtained from New England Nuclear (Boston, USA) and Amersham UK Ltd, Waymouth MB 752/1 was supplied by Flow Labs, Rickmansworth, UK. Acetylsalicylic acid, prostaglandin $\mathrm{F} 2 \alpha$, prostaglandin E2, ascorbic acid, and hydrocortisone were from Sigma (UK) and diclofenac from Ciba Geigy (UK). Sepharose 2B and 4B were from Pharmacia, Milton Keynes, UK.

\section{ORGAN CULTURE}

Gall bladders were collected fresh from patients undergoing routine open cholecystectomy. Upon removal gall bladders were opened, rinsed and immersed in ice cold isotonic saline $4^{\circ} \mathrm{C}$. The fundus and neck of the gall bladder were taken for histology. The mucosa from the body of the gall bladder was then peeled from the underlying muscle and peritoneum and 20 to 50 small explants of mucosa weighing 1-5 mg were prepared using two scalpels to dissect a $80-100 \mathrm{mg}$ piece of tissue. This was placed on a $3.2 \mathrm{~cm}$, $8 \mu \mathrm{m}$ pore size, ashless filter (Whatman, Maidstone, UK). A single filter was placed in a $5 \mathrm{~cm}$ Petri dish (Sterilin, Hounslow, UK) with $1 \mathrm{ml}$ organ culture medium. The maximum time from collecting a gall bladder to placing in the organ culture incubator was one hour.

Organ culture medium consisted of Waymouth MB 752/1 medium to which was added $10 \%$ fetal calf serum $(1 \mathrm{ml} / 10 \mathrm{ml})$, ascorbic acid (300 $\mu \mathrm{g} / \mathrm{ml})$, ferrous sulphate $(0.45 \mu \mathrm{g} / \mathrm{ml})$, hydrocortisone $(3 \mu \mathrm{g} / \mathrm{ml})$ and a mixture of penicillin, streptomycin, and mycostatin (100 $\mathrm{IU} / \mathrm{ml}$ ). To this solution was added ${ }^{3} \mathrm{H}$ glucosamine at a concentration of $74 \mathrm{KBq} / \mathrm{ml} .^{15}$

Culture was carried out for 24 hours in 5\% $\mathrm{CO}_{2}, 95 \% \mathrm{O}_{2}$ (humidified) at $37 \%$ (Heraeus, Hanau, W Germany). Gall bladder viability was assessed at $0,6,12$, and 24 hours using histological staining with haematoxylin and eosin and periodic acid/Schiff. ${ }^{16}$ Histological sections were examined for evidence of cell necrosis and depletion of intracellular mucin stores.

At the end of the incubation explants were rinsed and then homogenised in $0 \cdot 1 \mathrm{M} \mathrm{KH}_{2} \mathrm{PO}_{4} /$
Correspondence to: Mr $M$ Rhodes, FRCS Surgery, Frenchay Hospital, Frenchay, Bristol.

Accepted for publication 30 December 199 
$\mathrm{Na}_{2} \mathrm{HPO}_{4}$, containing $0.005 \mathrm{M}$ EDTA and 0.005 $M$ L-cysteine $\mathrm{HCl}$, using a rotating metal blade (Ultra Turrax, IKA Werk, W Germany). Specimens were then proteolytically digested for 72 hours at $60^{\circ} \mathrm{C}$ using papain (Sigma UK) at $0 \cdot 185$ $\mathrm{mg} / \mathrm{ml}$. After digestion samples were dialysed against distilled water over six days (three changes per day) to remove non-incorporated radioactivity and digested protein leaving the non-dialysable fragmented mucin. ${ }^{17}$

Acetylsalicylic acid was dissolved in $0.9 \%$ $\mathrm{NaCl}$ to make a stock solution of $2 \mathrm{mg} / \mathrm{ml}(\mathrm{pH}$ $7 \cdot 5$ ). Stock was added to tissue culture plates to give concentrations of 10 to $666 \mu \mathrm{g} / \mathrm{ml}$. Diclofenac sodium $(15 \mathrm{mg} / \mathrm{ml})$ was added to organ culture plates to give a final concentration of between $125 \mu \mathrm{g} / \mathrm{ml}$ and $1250 \mu \mathrm{g} / \mathrm{ml}$. Prostaglandin $\mathrm{F} 2 \alpha$ and prostaglandin E2 were added to organ culture plates at concentrations from 1 to $50 \mu \mathrm{g} / \mathrm{ml}$.

\section{CSCl DENSITY GRADIENT FRACTIONATION AND} SEPHAROSE 2B AND 4B CHROMATOGRAPHY The size and distribution of radiolabelled macromolecules in pooled gall bladder mucosal explants was characterised by caesium chloride density centrifugation and gel filtration on $150 \times 1.5 \mathrm{~cm}$ sepharose $4 \mathrm{~B}$ and $2 \mathrm{~B}$ columns. Each assay was repeated at least three times to establish reproducibility.

Samples studied on sepharose 2B were first fractionated on a $\mathrm{CsCl}$ gradient. ${ }^{18}$ The starting density was $1.425( \pm 0.005)$ and the solution was centrifuged at $50000 \mathrm{rpm}$ (mean of $201100 \mathrm{~g}$ ) for 18 hours using a vertical rotor (Sorvall TV850, Dupont, Wilmington, USA). The gradient was then fractionated into nine $4 \mathrm{ml}$ fractions and each was analysed for protein, glycoprotein and radioactivity as well as density.

All samples for chromatography were eluted upwards using $0.2 \mathrm{M} \mathrm{NaCl} / 0.02 \% \mathrm{NaN}_{3}, 5 \mathrm{ml}$ fractions were collected and assayed for glycoprotein, ${ }^{19}$ protein, and radioactivity.

\section{STATISTICAL ANALYSIS}

Results from each organ culture plate were expressed as $\mathrm{fmol}^{3} \mathrm{H}$-glucosamine incorporated per gram wet weight. Wet weight was shown to correlate in a linear fashion with total tissue protein and total tissue DNA. Data were compared visually using histograms and statistically using the Francia Shapiro W' test to test for normality. Data were found to be normally

Figure 1: Incorporation of $H$-glucosamine into human gall bladder mucosal explants. Explants were cultured for 24 hours,

homogenised, digested with papain for 72 hours and dialysed for 144 hours to remove non-incorporated radiactivity and lowmolecular weight glycoprotein.

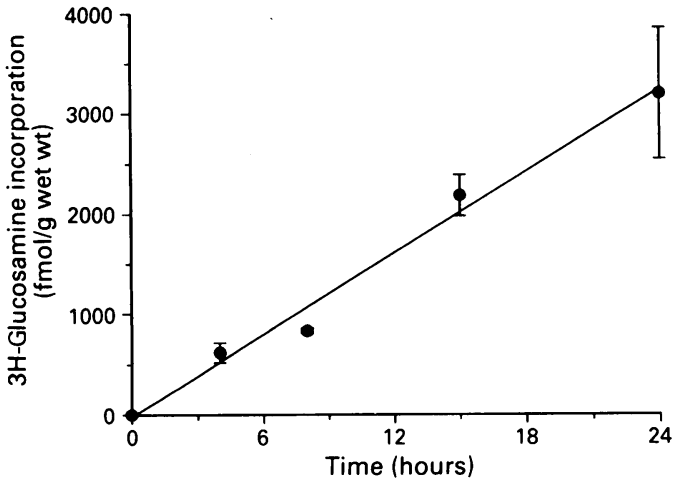

distributed and the unpaired $t$ test was used to compare the different groups.

\section{Results}

Incorporation of ${ }^{3} \mathrm{H}$-glucosamine by papain digested tissue explants was 3199 (SD 654) $\mathrm{fmol} / \mathrm{g}$ wet wt over 24 hours and linear with time (Fig 1). Incorporation was linear in both control and aspirin treated cultures dishes. ${ }^{3} \mathrm{H}$ glucosamine incorporation was reduced to 855,340 , and $75 \mathrm{fmol} / \mathrm{g}$ wet wt by sodium azide (an inhibitor of aerobic metabolism) at concentrations of 20,100 , and $500 \mu \mathrm{g} / \mathrm{ml}$ respectively. Histological examination of cultured explants revealed no evidence of cell death or depletion of intracellular mucin.

Evidence that over $90 \%$ of the radioactivity in papain digested explants was incorporated into gall bladder mucin was obtained as follows. Fractionation of homogenised but undigested explants by $\mathrm{CsCl}$ yielded a single radioactive peak banding at a density between 1.48 and 1.55 , coincident with standard undigested human biliary mucin. Fractionation of papain digested explants by $\mathrm{CsCl}$ yielded a single radioactive peak banding at a density between 1.49 and 1.55 , coincident with standard papain digested human biliary mucin. Gel filtration on sepharose 2B of the radioactive peaks after $\mathrm{CsCl}$ fractionation gave a single excluded peak for undigested explants and a single included peak for papain digested explants. These peaks were coincident with those for undigested and papain digested human biliary mucin respectively (Fig 2 ).

The addition of acetyl salicylic acid to the culture medium caused dose dependant inhibition of ${ }^{3} \mathrm{H}$-glucosamine incorporation (Fig 3). At a concentration of $230 \mu \mathrm{g} / \mathrm{ml}$ significant inhibition of mucus biosynthesis was achieved $(\mathrm{p}<0.04,95 \%$ CI 95, 620). A second nonsteroidal anti-inflammatory agent, diclofenac also significantly inhibited mucin biosynthesis. ${ }^{3} \mathrm{H}$-glucosamine incorporation was reduced from 1811 (SD 542) fmol/g wet wt in controls to 814 (SD 333) fmol/g wet wt in cultures to which 250 $\mu \mathrm{g} / \mathrm{ml}$ of diclofenac had been added $(\mathrm{p}=0.05$, $95 \%$ CI $-24,2017$ ). This inhibition of mucin biosynthesis as measured by ${ }^{3} \mathrm{H}$-glucosamine incorporation was irreversible after three hours incubation in acetyl salicylic acid at a dose of 300 $\mu \mathrm{g} / \mathrm{ml}$.

Analysis of pooled explant cultures on Sepharose $4 B$ confirmed again that $>90 \%$ of radioactivity was incorporated into mucus glycoprotein. The remainder of radioactivity was found in a small molecular weight PAS positive material (Fig 4) in the included volume of the column. Further analysis of pooled explants cultured in acetyl salicylic acid (Fig 4) at a dose of $300 \mu \mathrm{g} / \mathrm{ml}$ showed inhibition of incorporation into the mucin peak while incorporation of ${ }^{3} \mathrm{H}$ glucosamine into the minor low molecular weight glycoprotein peak was unaffected. Control experiments in which sodium azide was added to culture plates showed inhibition of incorporation into the mucin peak and the low molecular weight glycoprotein peak.

Addition of prostaglandin $\mathrm{F} 2 \alpha$ to the explant cultures at a dose of $10 \mu \mathrm{g} / \mathrm{ml}$ increased ${ }^{3} \mathrm{H}$ - 

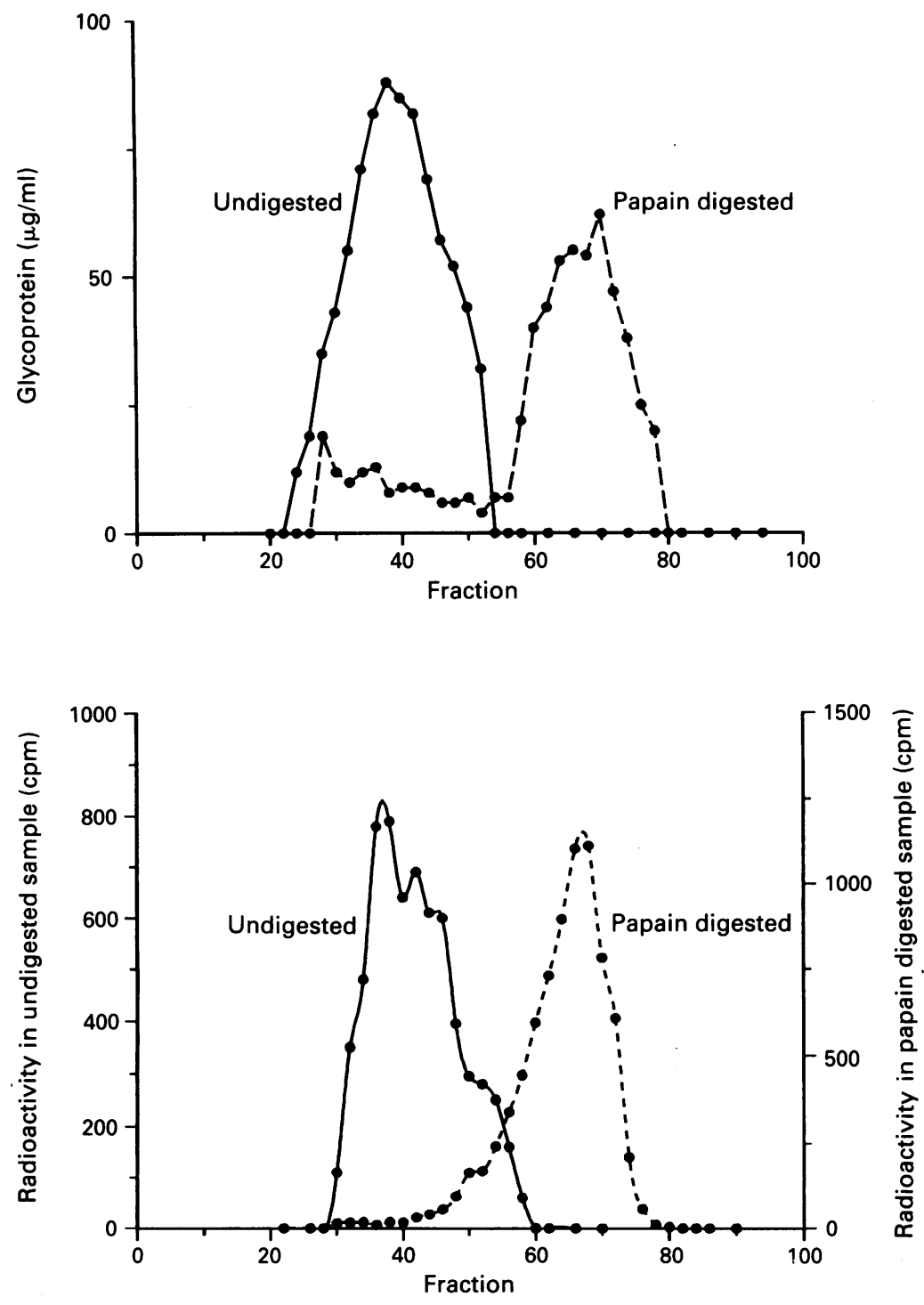

Figure 2: Glycoprotein and ${ }^{3} \mathrm{H}$-glucosamine content of undigested and papain digested mucosal explants. Mucosal explants were homogenised after 24 hour in tissue culture and either immediately fractionated on caesium chloride or

fractionated after papain digestion. Mucus glycoprotein fractions were then separated on Sepharose $2 B$. Undigested material was excluded on Sepharose 2B. After papain digestion glycoprotein from mucosal explants was included in the column.

Figure 3: Inhibition of mucus synthesis by differing doses of acetyl salicylic acid. Each data point is the mean of six separate experiments with standard errors shown in each case. ${ }^{\star} p=0.02,95 \%$ CI 95, 620. ${ }^{\star \star}{ }^{\star} p<0.0001$, $95 \%$ CI 410, 649.

$\star \star \star p<0.0001,95 \%$ CI

646, 851 . glucosamine incorporation from 1453 (SD 197) $\mathrm{fmol} / \mathrm{g}$ wet wt to 2314 (SD 696) fmol/g wet wt $(p<0 \cdot 1,95 \%$ CI 290,2013$)$ while at a dose of 50 $\mu \mathrm{g} / \mathrm{ml}$ biosynthesis as measured by ${ }^{3} \mathrm{H}$-glucosamine incorporation, was reduced to 707 (SD 48) $(\mathrm{p}=0.007,95 \% \mathrm{CI} 424,1070)$. The addition of prostaglandin E2 at doses between 1 and 25 $\mu \mathrm{g} / \mathrm{ml}$ had no influence on mucin biosynthesis.

\section{Discussion}

This series of experiments establishes a method for measuring ${ }^{3} \mathrm{H}$-glucosamine incorporation into mucin by human gall bladder mucosal explants. A previously documented organ

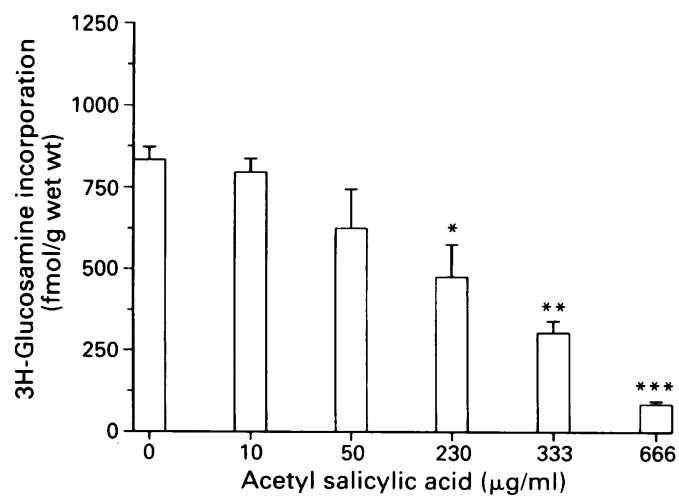

explant culture method was used. ${ }^{15} 16$ Cell viability was confirmed histologically and by the linear incorporation of ${ }^{3} \mathrm{H}$-glucosamine into mucin over the full time course of the experiment. Mucin biosynthesis is a very energy dependant process ${ }^{20}$ and therefore itself provides a sensitive biochemical assay of cell viability under the conditions used. This is documented in this system by the total inhibition of ${ }^{3} \mathrm{H}$ glucosamine incorporation into mucin in the presence of azide.

Radioactive incorporation into mucin was measured after first removing protein by papain digestion and dialysis. ${ }^{15}$ Protein digestion also removes part of the mucin protein core to leave the large molecular sized non-dialysable, degraded, glycosylated, mucin fragments containing the radioactively labelled carbohydrate.

This study also shows, for the first time, the selective inhibition of mucin biosynthesis by acetyl salicylic acid in human gall bladder mucosal explants. This finding is consistent with previous work, which showed that aspirin inhibits glycoprotein biosynthesis in the human gastric mucosa ${ }^{21}$ and the prairie dog gall bladder mucosa ${ }^{10}$ Possible mechanisms for inhibition of mucin biosynthesis by aspirin include a reduction in prostaglandin levels or depletion of cellular energy.

The in vitro action of aspirin at a dose of 230 $\mu \mathrm{g} / \mathrm{ml}$ is compatible with a role for the drug in vivo. The inhibition of mucus glycoprotein biosynthesis by acetyl salicylic acid may be one reason for its action in the prevention of gall stones. ${ }^{12}{ }^{13}$ Other anti-inflammatory properties of the drug may also prove important in gall stone prevention. ${ }^{14}$ Mucin is found at the centre of cholesterol gall stones ${ }^{26}$ and accelerates nucleation in model bile. ${ }^{22} 23$ Mucin also accelerates cholesterol nucleation in the gall bladder bile of the prairie dog' and has been shown to increase nucleation in human gall bladder bile. ${ }^{2+}$ Furthermore, both synthesis and secretion of mucin are increased before stone formation in the cholesterol fed prairie dog model. ${ }^{9}$

Inspite of this large amount of data linking mucin with gall stone formation it has been difficult to differentiate between gall stone patients and normal controls on the basis of total gall bladder bile mucin concentrations. ${ }^{25}$ This may be because studies have not been able to examine patients during the critical phase of gall stone initiation and any transient differences in gall bladder mucin synthesis (as showed in the prairie dog model) will have long passed in patients with mature gall stones. Several studies $^{1+2627}$ have identified glycoproteins of between 60000 Daltons and 130000 Daltons which appear to act as potent nucleating agents in human gall bladder bile and appear in greater concentrations in the bile of gall stone patients but their role in the pathogenesis of gall stones is far from clear. Mucin, however, has been more closely linked with gall stone formation in that increased synthesis and secretion occur before gall stone formation in the animal model. Mucin itself causes nucleation of cholesterol in both model and native gall bladder bile and is found at the centre of human cholesterol gall stones..$^{356}$

This study has shown selective inhibition of 


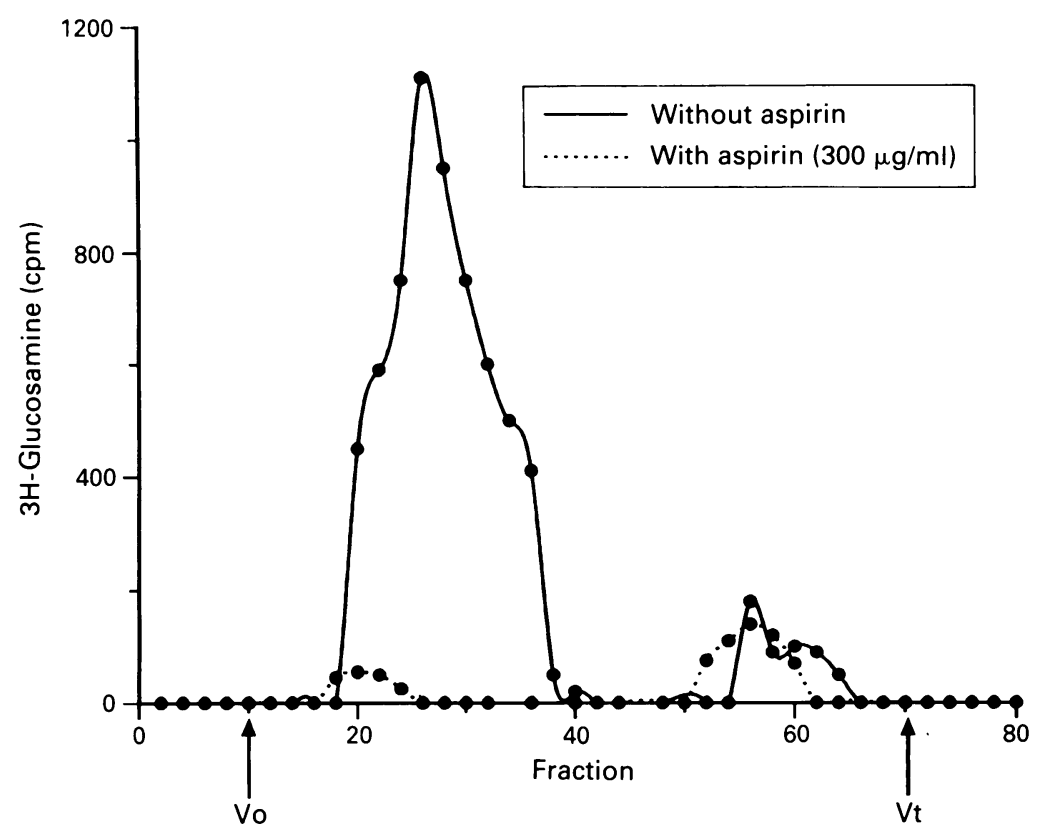

Figure 4: Glycoprotein and ${ }^{3} \mathrm{H}$-glucosamine content in human gall bladder mucosal explants. Explants were homogenised after 24 hours in tissue culture, then digested in papain for 72 hours and dialysed for 144 hours. Pooled samples were then run on Sepharose 4B.

${ }^{3} \mathrm{H}$-glucosamine was incorporated in parallel with glycoprotein, $>90 \%$ in mucus glycoprotein and $<10 \%$ in low molecular weight glycoprotein. ${ }^{3} \mathrm{H}$ glucosamine incorporation into explants cultured without acetyl salicylic acid are shown by the solid line, those cultured with acetyl salicyclic acid at a dose of $300 \mathrm{\mu g} / \mathrm{ml}$ by the broken line. Acetyl salicylic acid selectively inhibits incorporation of ${ }^{3} \mathrm{H}$ glucosamine into the mucin glycoprotein peak.

mucin biosynthesis in explanted human gall bladder mucosa. The concentrations of aspirin needed to inhibit mucin synthesis may well be compatible with an in vivo role for the drug. These observations provide one explanation for the observations that aspirin may prevent new gall stone formation and gall stone recurrence after successful oral dissolution therapy. Further in vivo studies in man are warranted.

This work was funded by the Newcastle Health Authority Scientific and Research Committee and the University of New castle upon Tyne William Edmund Harker Bequest. Our thanks also to Mr R M Coan and Mrs S Cooke for technical assistance.

1 Womack N, Zeppa R, Irvin G. The anatomy of gallstones. Ann Surg 1963; 157: 670-86.

2 Maki T, Matsushiro T, Susuki N, Nakamura N. Role of sulphated glycoprotein in gallstone formation. Surg Gynecol Obstet 1971; 132: 846-51

3 Smith BF, LaMont JT. Bovine gallbladder mucin binds bilirubin in vitro. Gastroenterology 1983; 85: 707-12.

4 Lee SP. Hypersecretion of mucus glycoproteins by gallbladde epithelium in experimental cholelithiasis. $\mathcal{F}$ Pathol 1981;
7 Bouchier IAD, Cooperband SR, ElKodsi BM. Mucous substances and viscosity of normal and pathological human bile. Gastroenterology 1965; 49: 343-53.

8 Freston JW, Bouchier IAD, Newman J. Biliary mucous substances in dihydrocholesterol-induced cholelithiasis. Gastroenterology 1969; 57: 670-8.

9 Lee SP, LaMont JT, Carey MC. Role of gallbladder mucus hypersecretion in the evolution of cholesterol gallstones f Clin Invest 1981; 67: 1712-23.

10 Lee SP, Carey MC, LaMont JT. Aspirin prevention of cholesterol gallstone formation in prairie dogs. Science 1981 211: 1429-31.

11 LaMont JT, Turner BS, DiBenedetto D, Hadin R, Schafer AI. Arachidonic acid stimulates mucin secretion in prairie dog gallbladder. Am $\mathcal{F}$ Physiol 1983; 245: G92-8

12 Broomfield PH, Chopra R, Sheinbaum RC, Bonoris GC, Silverman A, Schoerifield LJ, et al. The effects of ursodeoxycholic acid and aspirin on the formation of lithogenic bile and gallstones during loss of weight. $N \mathrm{EnglF}$ Med 1988; 319: 1567-72.

13 Hood K, Gleeson D, Ruppin DC, Dowling RH. Prevention of gallstone recurrence by non-steroidal anti-inflammatory gallstone recurrence by non-st
drugs. Lancet 1988 ; ii: $1223-5$.

14 Upadhya GA, Harvey PRC, Strasberg SM. The potent pronucleating proteins in gallbladder bile of cholestero gallstone patients are polymeric immunoglobulins. Gastroenterology 1991; 100: A807.

15 Hunter AC, Allen A, Garner A. Studies on mucus biosynthesis in the gastrointestinal tract. In: Chantler E, Ratcliffe NA eds. Mucus and related topics. Society for Experimental Biology, 1989. London \& Sydney.

16 Allan A, Jewell DP. In vitro model for assessment of luminal factors in rectal mucosa. Gut 1983; 24: 812-7.

17 Allen A. Gastrointestinal mucus. Handbook of physiology vol 111. Bethesda, USA: American Physiological Society, 1989: 359-82. 134: 199-207.

5 Doty JE, Pitt HA, Kuchenbecker SL, Porter-Fink V, Den Besten LW. Role of gallbladder mucus in the pathogenesi of cholesterol gallstones. Am $\mathcal{F}$ Surg 1983; 145: 54-60.

6 Pearson JP, Foster SNE. Mucus glycoprotein content of human cholesterol gallstones. Digestion 1987; 36: 132-40.
18 Pearson JP, Kaura R, Taylor W, Allen A. The composition and polymeric structure of mucus glycoprotein from hum

19 Mantle M, Allen A. A colorimetric assay for glycoproteins based on the periodic acid/Schiff reaction. Biochem Soc Tran $1978 ; 6: 607-9$

20 Neutra MR, Forster JF. Gastrointestinal mucus - synthesis, secretion and function. In: Johnson LR, ed. Physiology of the gastrointestinal tract. Vol 3. New York: Raven Press, 1987 975-1009.

21 Kent PW, Allen A. The biosynthesis of intestinal mucins. The effect of salicylate on glycoprotein biosynthesis by sheep colonic and human gastric mucosal tissues in vitro. Biochem

22 Levy PF, Smith BF, LaMont JT. Human gallbladder mucin accelerates nucleation of cholesterol in artificial bile. Gastroenterology 1984; 87: 270-5.

23 Smith BF. Human gallbladder mucin binds biliary lipids and promotes cholesterol crystal nucleation in model bile. $\mathcal{f}$ Lipid Res 1987; 28: 1088-97.

24 Gallinger S, Taylor RD, Harvey PRC, Petrunka CN, Strasberg SM. Effect of mucous glycoprotein on nucleation time of human bile. Gastroenterology 1985; 89: 648-58. (MG) concentrations in normal and abnormal gallbladder (GB) bile and the effect of MG on nucleation time. Gastroenterology 1984; 86: A1319.

26 Groen AK, Noordam C, Drapers JAG, Egbers P, Jansen PLM, Tytgat GNJ. Isolation of a potent cholesterol nucleation promoting activity from human gallbladder bile. Role in tion promoting activity from human gallbladder bile. Role in the path.

27 Groen AK, de Brujin MAC, Goldhoorn BG, van Marle J, Tytgat GNJ. Con A-binding biliary protein contains a lipoprotein with nucleation promoting activity. Gastroenterology 1991; 100: A318. and polymeric structure of mucus glycoprotein from huma folonic and human 1968 : 645-58

25 Gallinger S, Harvey PRC, Strasberg SM. Mucous glycoprotein 